\title{
OUTPUT-ONLY MODAL CHARACTERIZATION FOR A CONCRETE BRIDGE
}

\author{
P.H.M. Barbosa ${ }^{1}$, T.G. Albino ${ }^{1}$, C. J. Martins ${ }^{1}$ \\ ${ }^{1}$ Department of Civil Engineering, Federal Centre of Technological Education (correspond- \\ ing-cjmartins@ civil.cefetmg.br)
}

\begin{abstract}
This study presents the methodology and results of a dynamic loading test carried out at bridge "Ponte do Canal de Sernambetiba" in Rio de Janeiro - Brazil. The applied technology considers the traffic, under normal conditions, and arbitrary environment loads as random input vibration sources. Eleven independent measurements were conducted on the bridge deck in order to detect the most important vibration modes. The acquired signals were processed by an algorithm based on Subspace Stochastic Identification (SSI) that computes the main structural resonances, damping and modal shapes. Afterwards, a numerical model of the structure, based on a Finite Elements Method, was created and calibrated according to the measured resonances. Finally, the validated model was applied in order to evaluate the response of the bridge under critical loading scenarios.
\end{abstract}

Keywords: Operational modal analysis, Digital signal processing, Finite Elements Method.

\section{INTRODUCTION}

Measurements and detections of natural vibrations of structures are well known procedures in the field of Experimental Modal Analysis or Modal Testing. Basically, this technique consists of a mechanical test, in which vibration loads or impacts are induced on the structure in order to determine its dynamic properties (natural frequencies, damping and vibration shapes). Given these dynamic parameters or modal parameters, it is possible to calibrate a pre-designed model by adjusting the material properties and mechanical restrictions until matching them with reality. This way, the calibrated model can finally be applied on integrity analysis of the structure and on simulations of the behavior of the structure under several load conditions (Maia[1], 1998).

The application of the Modal Testing has shown to be efficient in many situations, but usually, its application is restricted to small structures, in which it is feasible to induce artificial vibrations with impact hammer or electrodynamic shakers (He et al[2], 2001). However, in civil engineering, due to the physical dimensions of the structures, the introduction of artificial vibration is an expensive process and sometimes even impossible to carry out. These are mostly the case of bridges, buildings, towers and others. Additionally, the application of this technique can lead to the collapse of already damaged structures. One possible solution for dynamic testing on large structures is to conduct an advanced technique called Operational Modal analysis (OMA). This technique considers natural phenomena such as wind, traffic, movement of people and others as excitation sources. However, the application of this technique requires ultra-sensitive vibration measurements, around $10^{-8} \mathrm{~g}$. The main advantages of 
the use of this technique are cost and time reductions.

This article presents an application of an Operational Modal Analysis (OMA) carried out on the concrete bridge "Ponte do Canal de Sernambetiba" built in the 1960's, Rio de Janeiro - Brazil. Computational techniques based on Stochastic Subspace Identification were conducted in order to identify the modal parameters. Damages could be detected during the calibration of the model showing the advantages and suitability of the method, (Jeary[3], 2002).

\section{NUMERICAL MODEL}

\subsection{Overview}

The bridge's superstructure is characterized as a continuous structure with a total length of 140 meters, encompassing two extremity spans of $40 \mathrm{~m}$ length each and a central span of $60 \mathrm{~m}$ length. The superstructure is supported in its extremities by ground fixed concrete structures, which contain the retraction joint. There are also two intermediate pillars, with dimensions of $1.1 \times 0.5 \mathrm{~m}$ and $4.2 \mathrm{~m}$ height from the terrain. Figures 1 to 4 show the studied bridge.

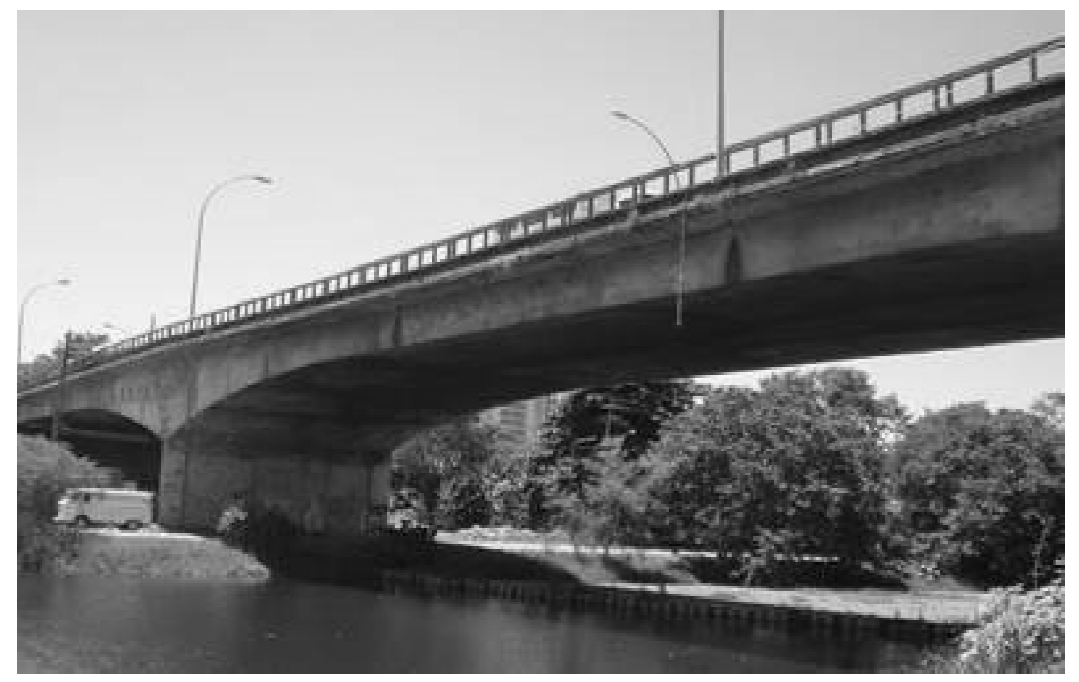

Figure 1. General view - left side of Bridge "Ponte do Canal de Sernambetiba".

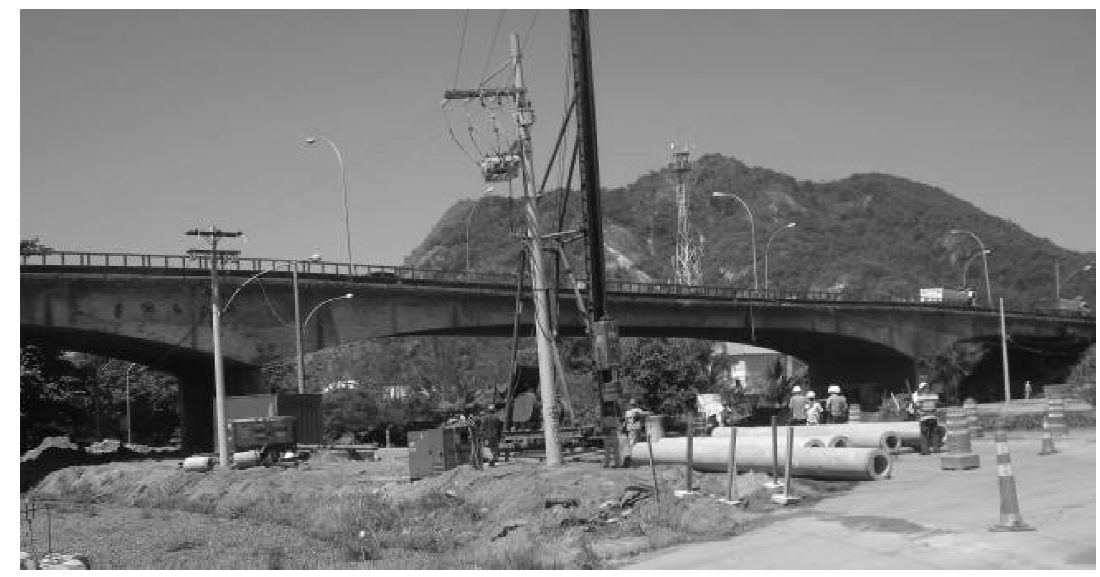

Figure 2. General view - right side of Bridge "Ponte do Canal de Sernambetiba". 


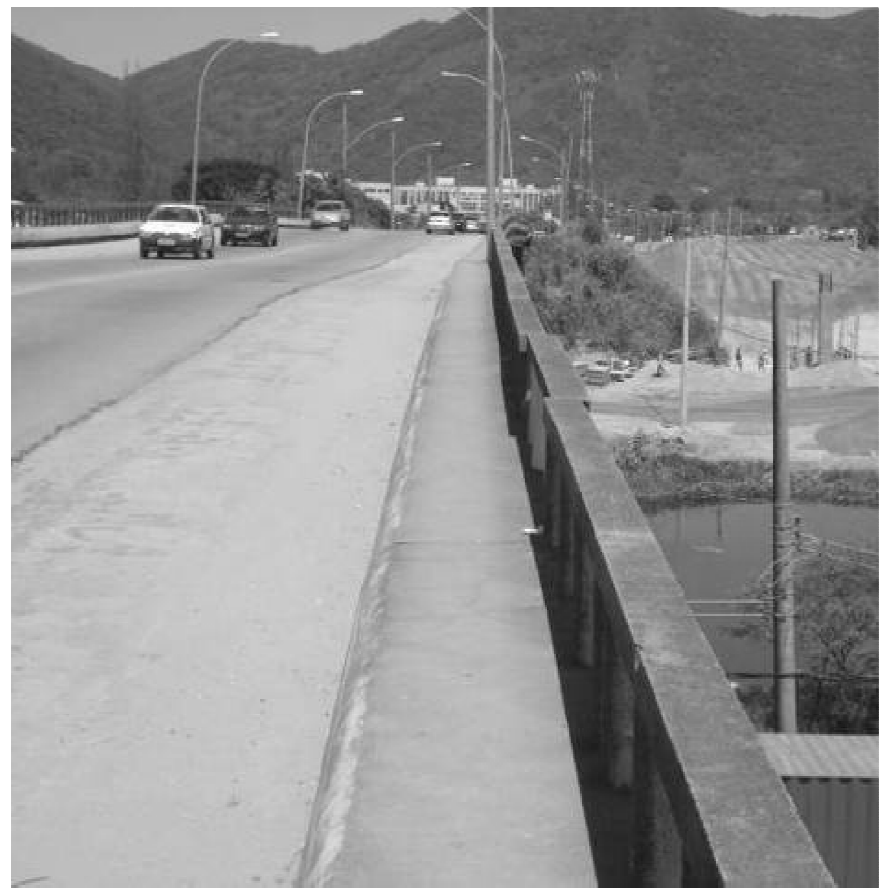

Figure 3. Superior view of Bridge "Ponte do Canal de Sernambetiba".

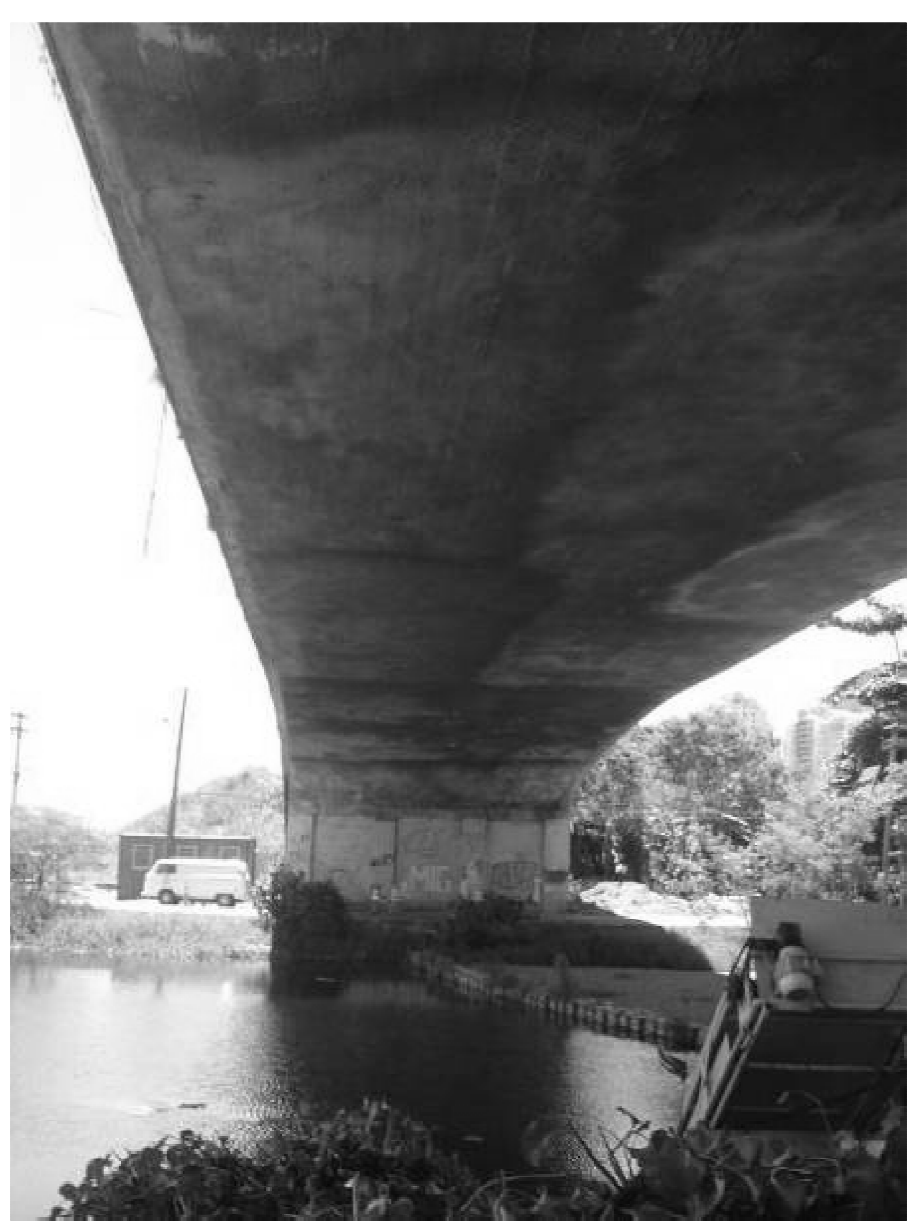

Figure 4. Inferior view of Bridge "Ponte do Canal de Sernambetiba". 


\subsection{Design of the initial model}

After conducting visual inspections and a topography survey, a numerical model of the structure was developed based on the Finite Elements Method. Additionally, during the inspection in the bridge's span, it was observed three closed cells with $20 \mathrm{~cm}$ thick walls that were also taken into account during the development of the model. The figure 5 to 9 depicts this initial bridge's model.

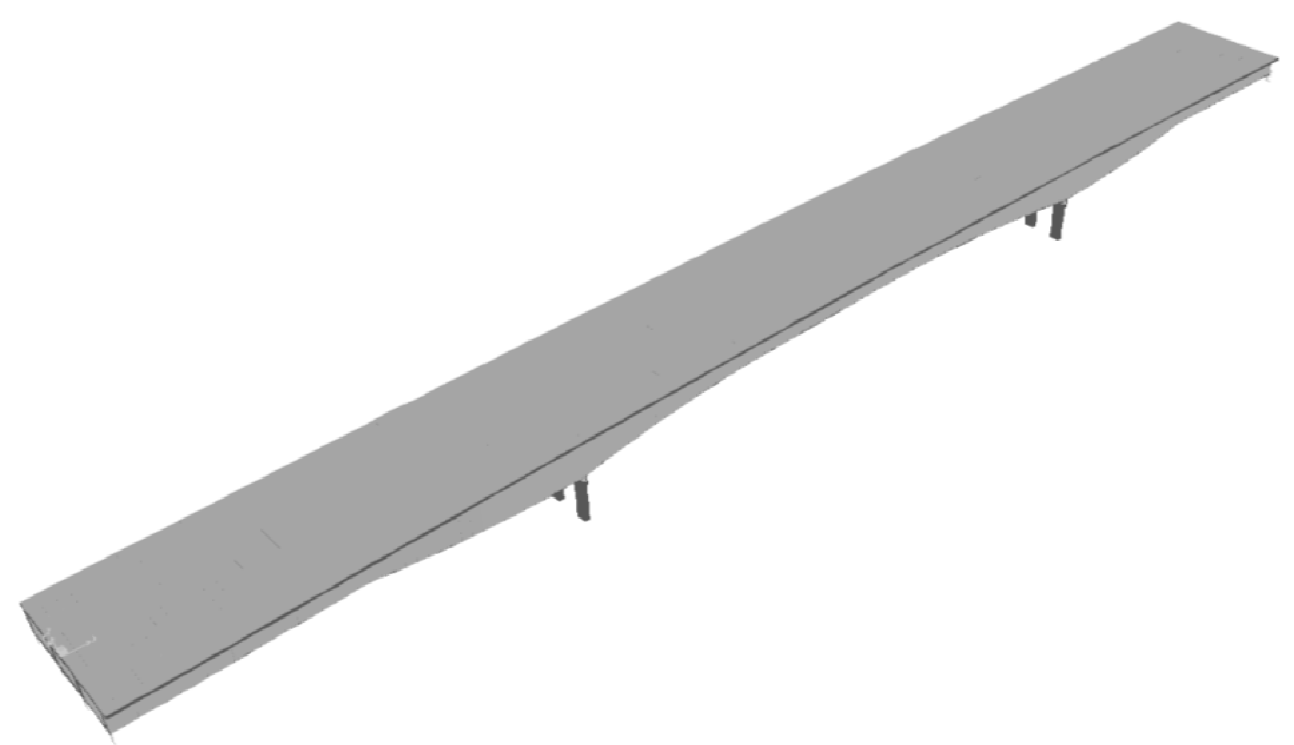

Figure 5. Initial model perspective (superior view).

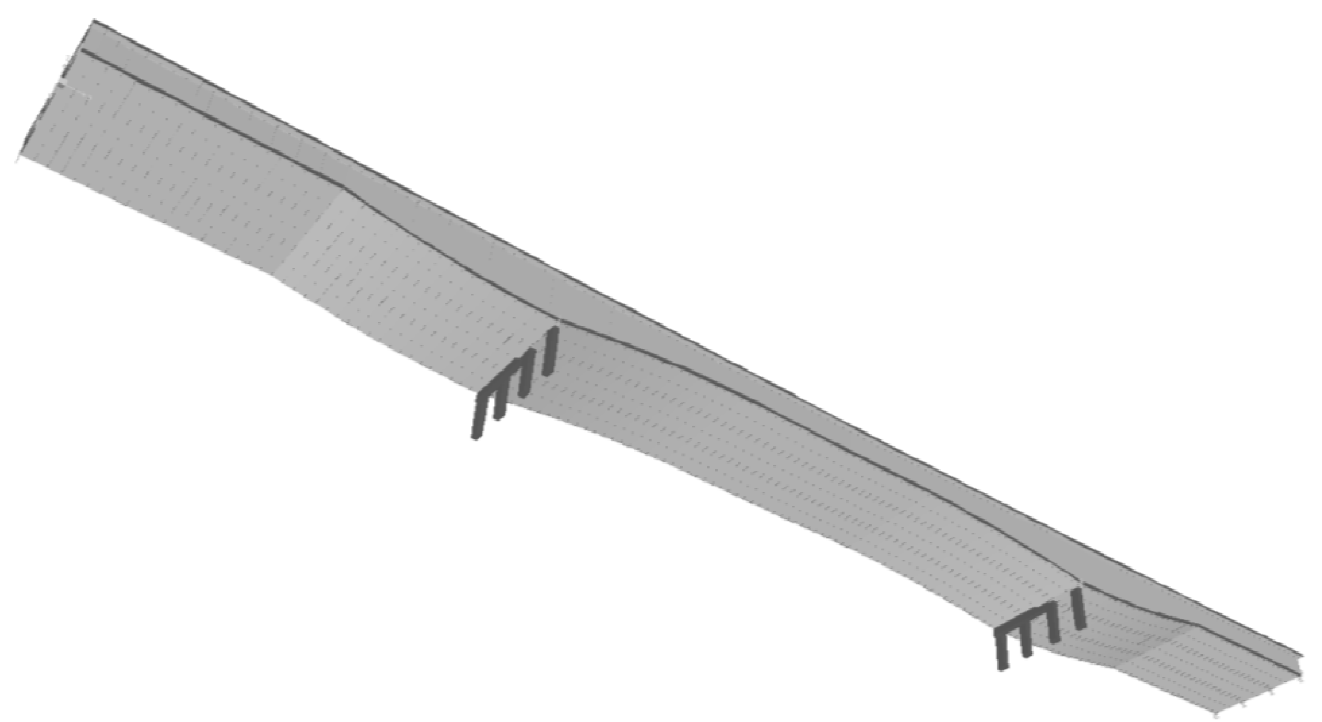

Figure 6. Initial model perspective (inferior view). 


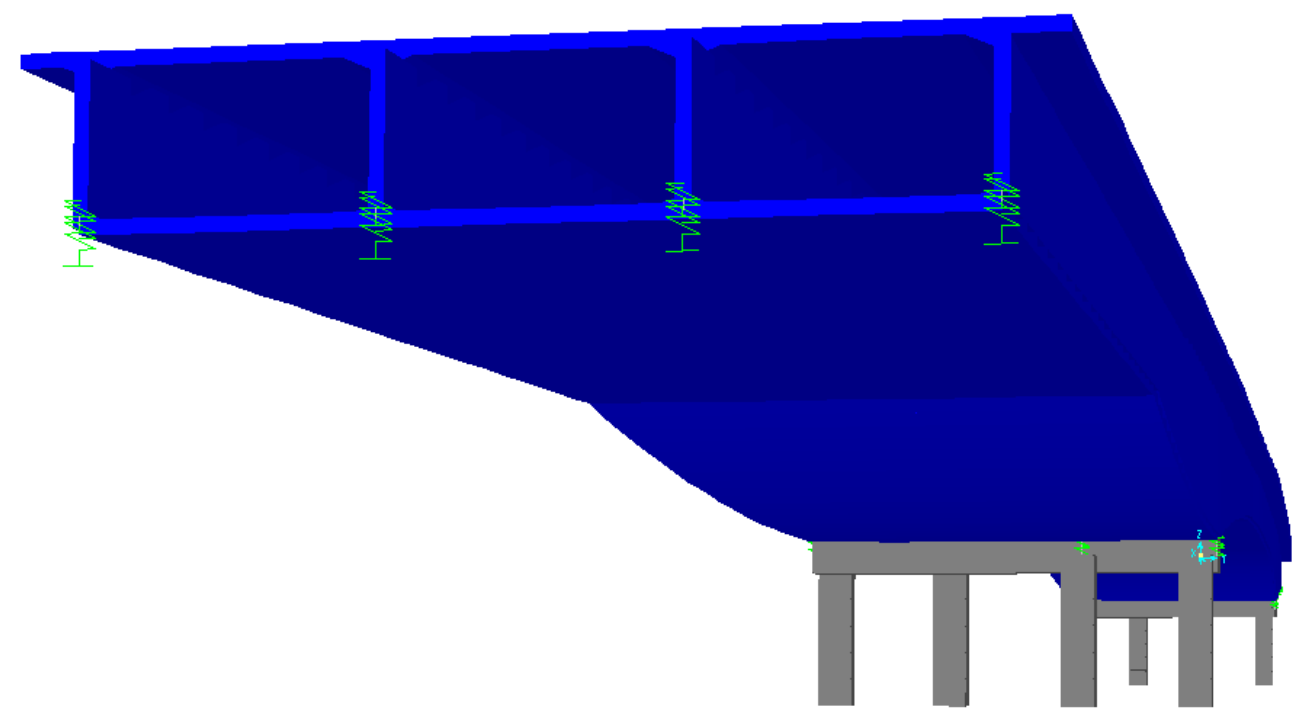

Figure 7. Initial model perspective (front view).

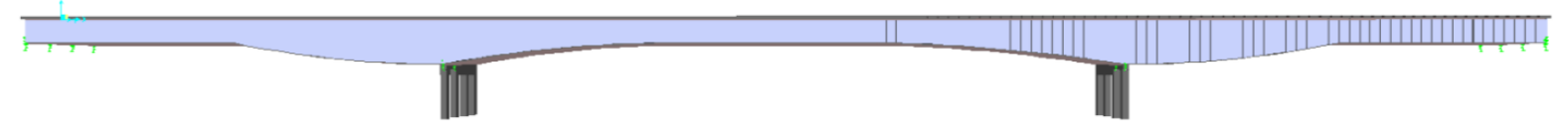

Figure 8. Initial model perspective (lateral view).

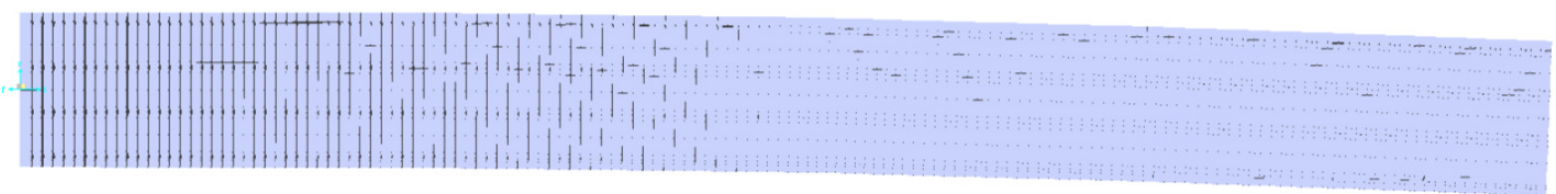

Figure 9. Initial model (superior view).

\subsection{Measuring}

At the same time during the development of the model, vibration measurements were conducted on the bridge's deck in order to detect the vibration modes. The graphs of figures 10 and 11 present one of the measurements result in both time and frequency domain for all selected measurement points.

Figure 11 shows, in frequency domain, the power spectral density function of the measurement signals. These functions represent the amount energy distributed on the frequency components and provide important information for the determination of the modal parameters when random loads are applied. It is important to report that showed peaks in this spectral curve may represent natural frequencies of the bridge or modal frequencies, the point is how to separate the peaks that belongs to the modal frequencies from others that are reflections of operational modes, (Jeary[4], 1992). 


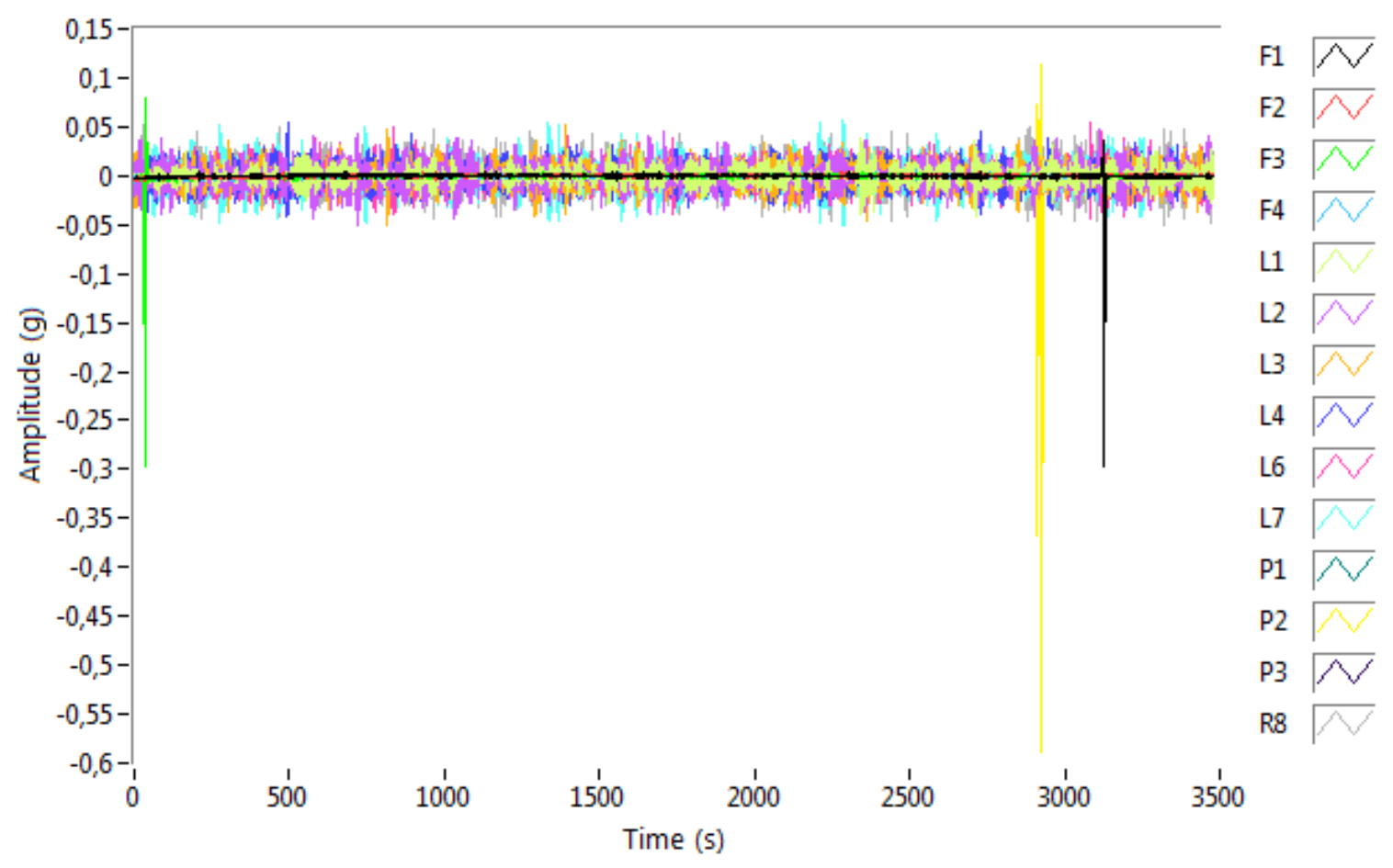

Figure 10. Acquired data in time domain.

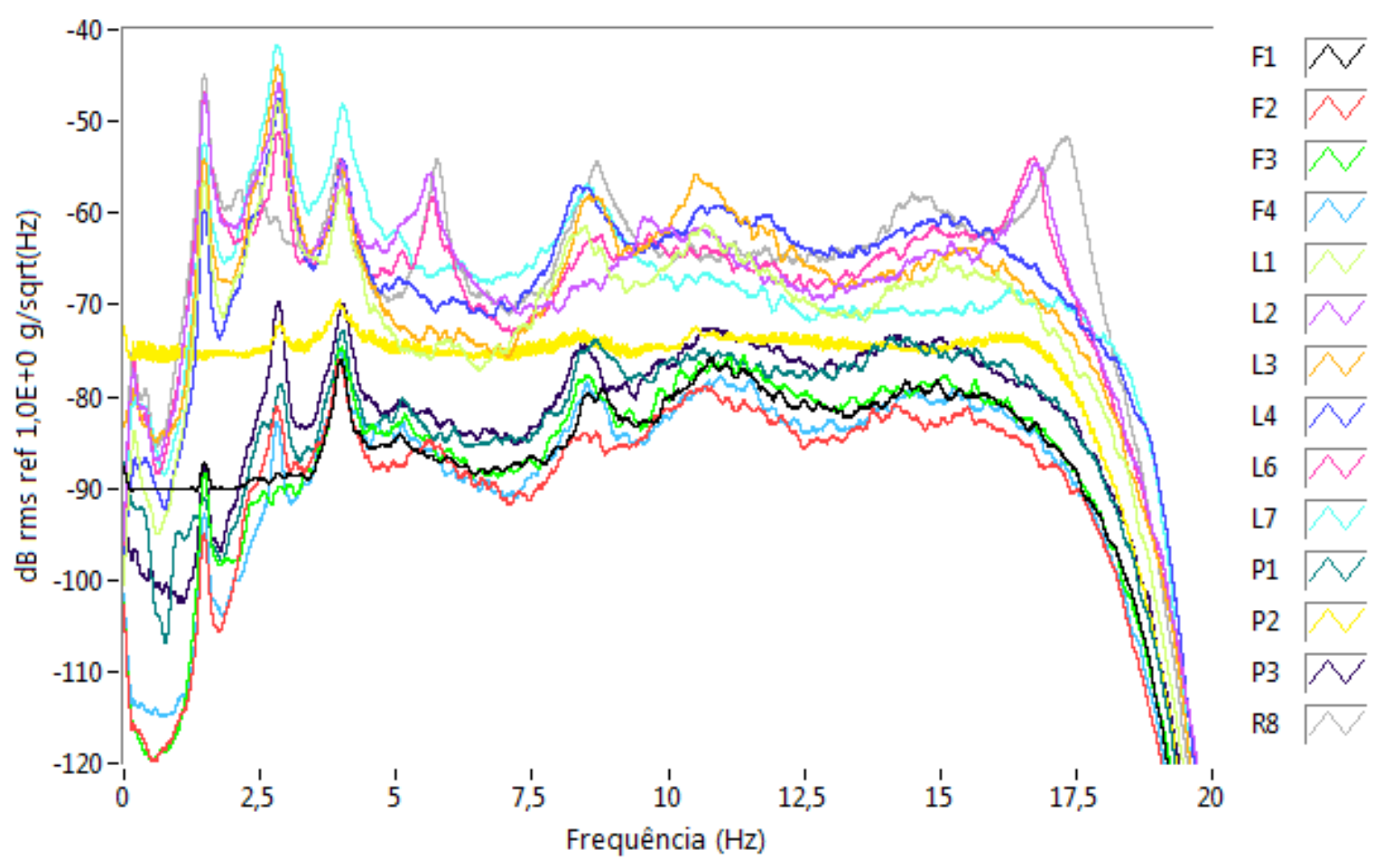

Figure 11. Acquired data in frequency domain. 


\subsection{Modal frequencies identification}

The identification of the modal frequencies was conducted by the following digital signal processing methods: filtering, signal decimation, removal of DC offset signal component and finally the extraction of the vibration modes. The procedure for obtaining vibration modes is based on the algorithm SSI for stochastic identification in subspace. This algorithms is based on the use of stochastic theory for Gaussian distributed stochastic processes, it is actually described by the spectral densities functions in frequency domain. One of the results is the stabilization diagram which is a powerful tool for detecting the modal frequencies, those whose points remains in vertical line. Figure 5 shows the stabilization diagram. Table 1 shows the obtained modal parameters for the chosen order (order 12 - Figure 5).

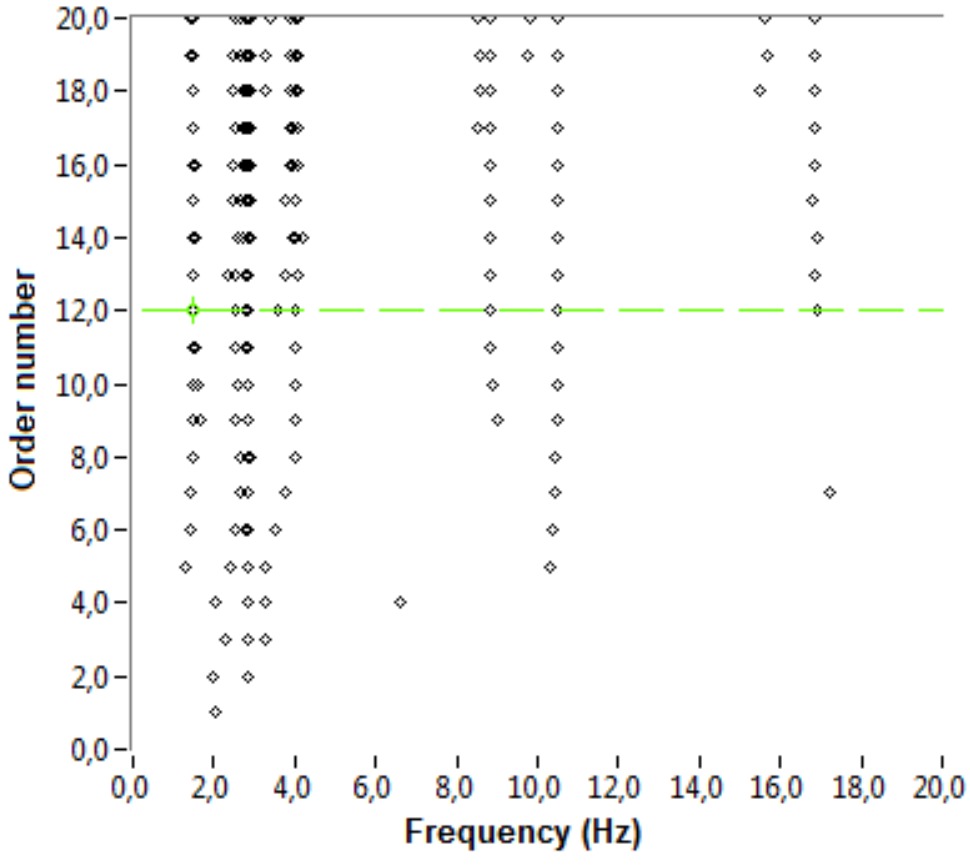

Figure 12. Acquired data in frequency domain.

Table 1. Extracted vibration modes by Stochastic Subspace Identification (SSI).

\begin{tabular}{c|c|c}
\hline $\begin{array}{c}\text { Possible identified } \\
\text { vibration modes }\end{array}$ & $\begin{array}{c}\text { Frequency } \\
(\mathrm{Hz})\end{array}$ & $\begin{array}{c}\text { Damping } \\
(\%)\end{array}$ \\
\hline \hline 1 & 1.456 & 1.77 \\
\hline 2 & 1.484 & 15.786 \\
\hline 3 & 2.535 & 6.869 \\
\hline 4 & 2.76 & 3.302 \\
\hline 5 & 2.852 & 0.529 \\
\hline 6 & 2.859 & 2,13 \\
\hline 7 & 2.865 & 5.417 \\
\hline 8 & 3.601 & 17.941 \\
\hline 9 & 4.04 & 3.597 \\
\hline 10 & 8.805 & 2.522 \\
\hline 11 & 10.493 & 2.197 \\
\hline 12 & 16.913 & 5.749 \\
\hline
\end{tabular}


From the initial geometry, some changes were done in the initial numerical model, in order to adjust natural frequencies obtained numerically to the experimental figures of Table 1. Such alterations consist in the introduction of damages to the initial numerical model (plastic articulations, loss of rigidity of the sections, alterations in the joints) in adequate positions and intensity, obtaining, thus, a "calibrated" numerical model, (Cole[5], 1973). Figures 13 and 14 present the results obtained. Table 2 shows the numerical figures.

It must be highlighted that only the nine first vibration modes of the structure were considered, once these modes present figures above $90 \%$ of the mobilized mass, as can be attested in Figure 15.

\section{CONCLUSION}

The studies employed advanced techniques of digital signal processing for detecting and adjusting natural frequencies, structural damping and modal shapes of a computing numerical model based on FEM (finite Elements Method). The calibrated model is a numerical approximation of the real structure after adjustments of the real model and it was used for structural analysis of the bridge.

From the structural verification in the bridge's calibrated model, it was possible to conclude that the bridge cannot stand the actions and events set by the Brazilian standard ABNT NBR-7187[6] (1987). The restoration of the structural bridge is feasible and it could be done by reinforcement of its pillars, increasing their transversal section, as well as general reinforcements at the spans, increasing the structural capacity and reinforcing the foundation by adding new stakes to the existing blocks.

\section{Acknowledgements}

The authors acknowledge the financial support by CEFET/MG, CNPq, CAPES and FAPEMIG

\section{REFERENCES}

[1] N. Maia, J.M. Silva, J. He, N. Lieven, N. Lin, R. Lin, G. Skingle, W.M. To, A. Urgueira, "Theoretical and Experimental Modal Analysis", Research Studies Press, London, England, 1998.

[2] J. He, Z. Fu, "Modal analysis, Butterworth-Heinemann", Oxford, England, 2001.

[3] Jeary A. P., " The identification of damage in large structures", Report UWS univ of western Sydney, Australia, 2002.

[4] Jeary, A.P., "Establishing Non-Linear Damping Characteristics of Structures from NonStationary response Time-Histories", The Structural Engineer, Vol. 70, No. 4, 18,1992.

[5] Cole H. A., " On line failure detection and damping measurements by random decrement signatures", NASA CR 2205, 1973.

[6] ABNT NBR-7187, "Projeto e execução de pontes de concreto armado e protendido", 1987. 


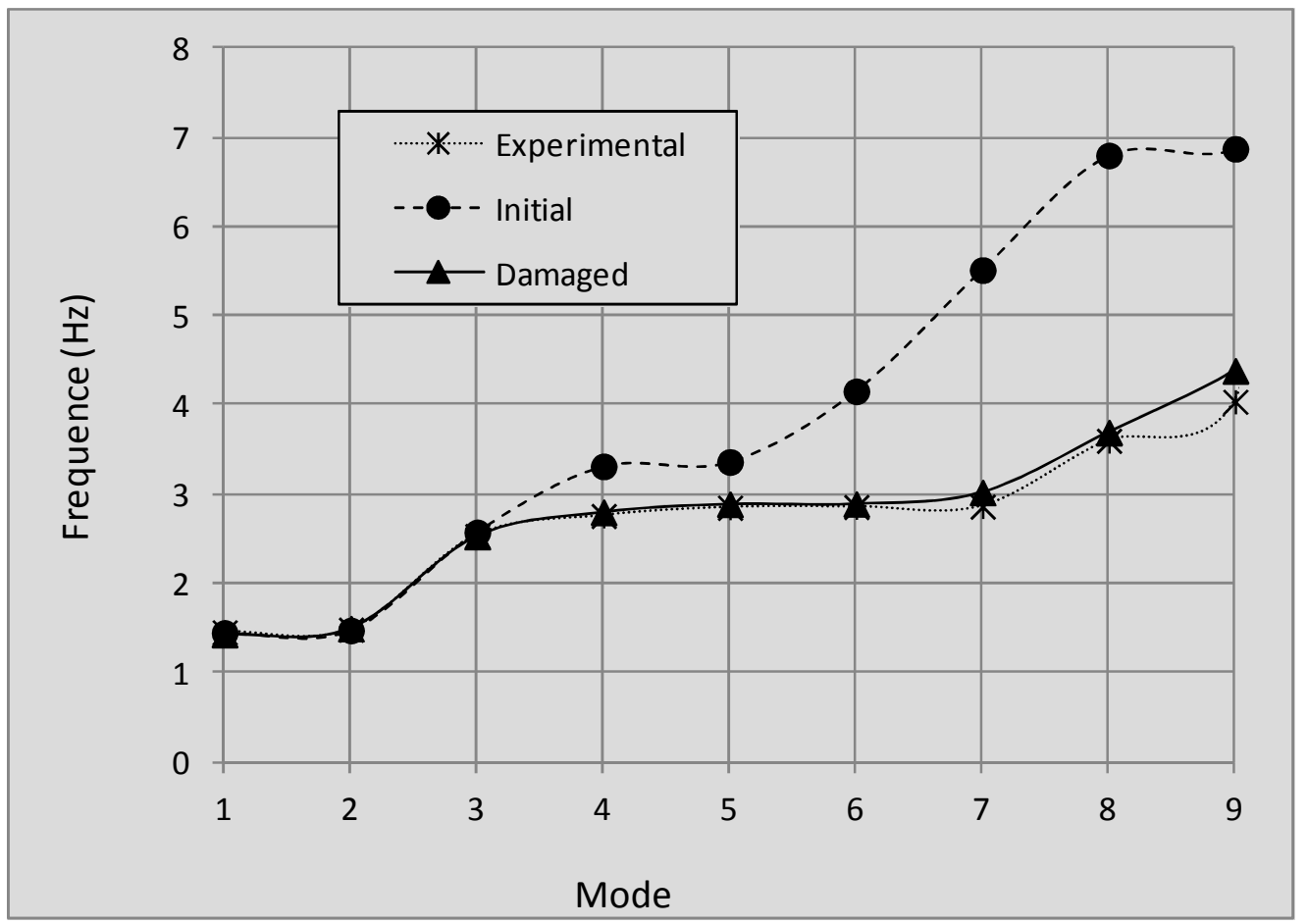

Figure 13. Experimental (detected), calibrated and initial natural frequencies.

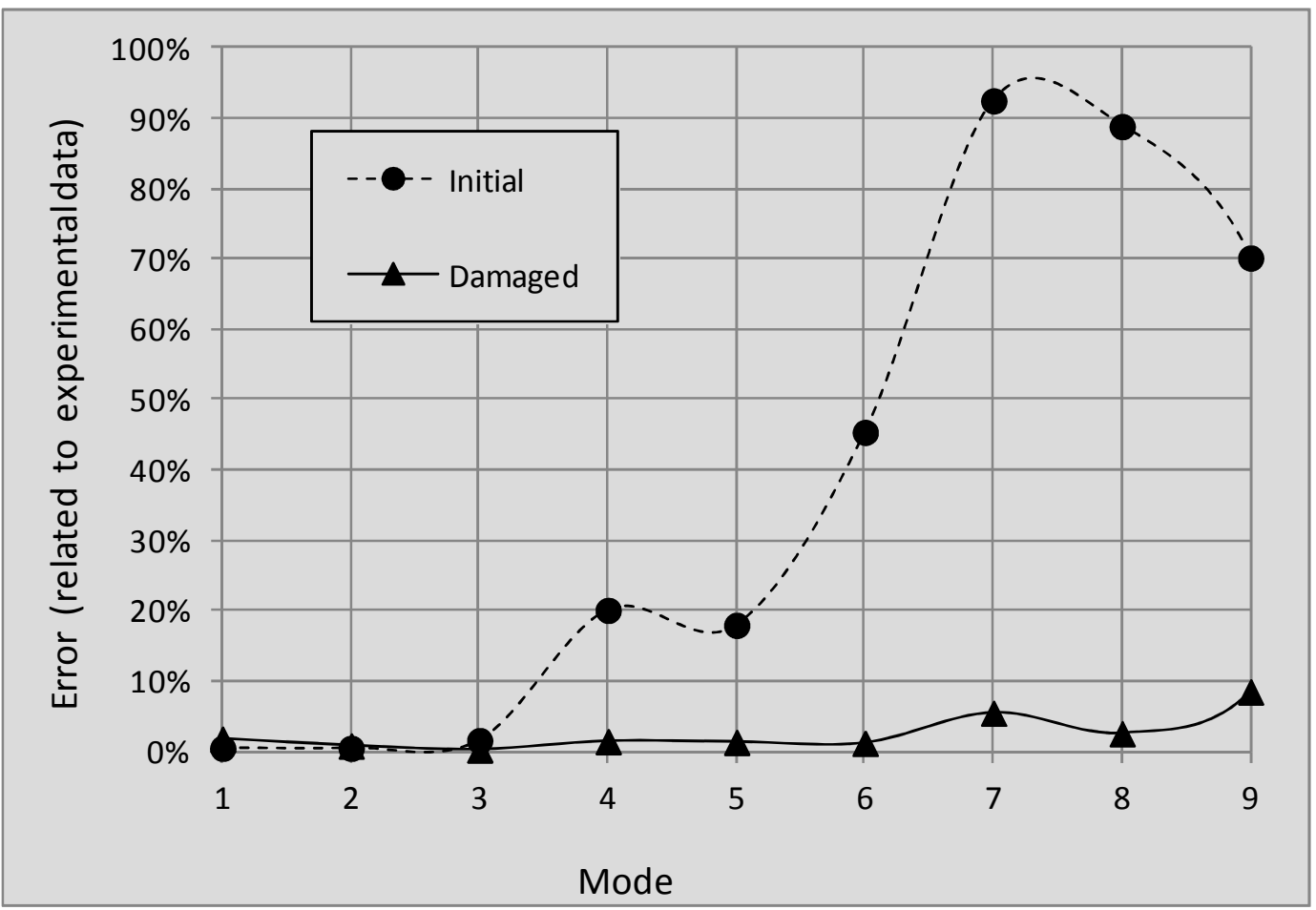

Figure 14. Error related to initial model and calibrated model. 
Table 2. Numerical characterization results.

\begin{tabular}{c|c|c|c|c|c}
\hline Mode & Experimental & \multicolumn{2}{|c|}{ Initial model } & \multicolumn{2}{c}{ Calibrated model } \\
& & \multicolumn{2}{c}{} \\
\hline & Freq. (Hz) & Freq. (Hz) & Error & Freq. (Hz) & Error \\
\hline \hline 1 & 1,46 & 1,45 & $1 \%$ & 1,43 & $2 \%$ \\
\hline 2 & 1,48 & 1,48 & $1 \%$ & 1,50 & $1 \%$ \\
\hline 3 & 2,54 & 2,58 & $2 \%$ & 2,53 & $0 \%$ \\
\hline 4 & 2,76 & 3,32 & $20 \%$ & 2,80 & $1 \%$ \\
\hline 5 & 2,85 & 3,36 & $18 \%$ & 2,89 & $1 \%$ \\
\hline 6 & 2,86 & 4,16 & $45 \%$ & 2,89 & $1 \%$ \\
\hline 7 & 2,87 & 5,52 & $93 \%$ & 3,02 & $5 \%$ \\
\hline 8 & 3,60 & 6,80 & $89 \%$ & 3,69 & $3 \%$ \\
\hline 9 & 4,04 & 6,87 & $70 \%$ & 4,38 & $9 \%$ \\
\hline
\end{tabular}

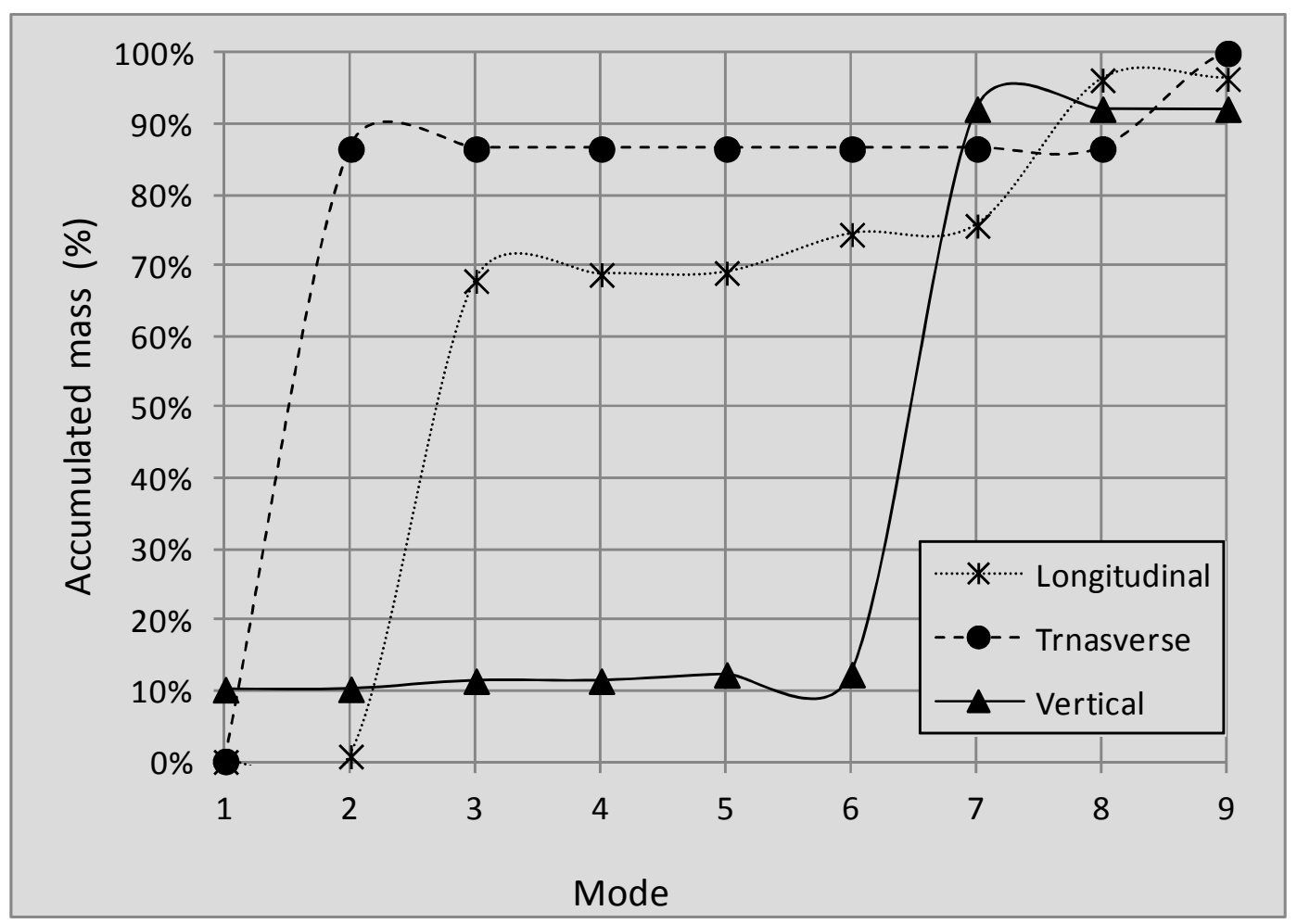

Figure 15. Percentage of accumulated mobilized mass. 